\title{
Hemodialysis catheter implantation in the axillary vein by ultrasound guidance versus palpation or anatomical reference
}

This article was published in the following Dove Press journal: International Journal of Nephrology and Renovascular Disease II October 2013

Number of times this article has been viewed

\author{
Cesar A Restrepo Valencia' \\ Carlos A Buitrago Villa' \\ Jose A Chacon Cardona ${ }^{2}$ \\ 'Internal Medicine, Nephrology, \\ ${ }^{2}$ Epidemiology, Caldas University, \\ Manizales, Colombia
}

Background: We compared the results of four different methods of hemodialysis catheter insertion in the medial segment of the axillary vein: ultrasound guidance, palpation, anatomical reference, and prior transient catheter.

Methods: All patients that required acute or chronic hemodialysis and for whom it was determined impossible or not recommended either to place a catheter in the internal jugular vein (for instance, those patients with a tracheostomy), or to practice arteriovenous fistula or graft; it was then essential to obtain an alternative vascular access. When the procedure of axillary vein catheter insertion was performed in the Renal Care Facility (RCF), ultrasound guidance was used, but in the intensive care unit (ICU), this resource was unavailable, so the palpation or anatomical reference technique was used.

Results: Two nephrologists with experience in the technique performed 83 procedures during a period lasting 15 years and 8 months (from January 1997-August 2012): 41 by ultrasound guidance; 19 by anatomical references; 15 by palpation of the contiguous axillary artery; and 8 through a temporary axillary catheter previously placed. The ultrasound-guided patients had fewer punctures than other groups, but the value was not statistically significant. Arterial punctures were infrequent in all techniques. Analyzing all the procedure-related complications, such as hematoma, pneumothorax, brachial-plexus injury, as well as the reasons for catheter removal, no differences were observed among the groups. The functioning time was longer in the ultrasound-guided and previous catheter groups. In 15 years and 8 months of surveillance, no clinical or image evidence for axillary vein stenosis was found.

Conclusion: The ultrasound guide makes the procedure of inserting catheters in the axillary veins easier, but knowledge of the anatomy of the midaxillary region and the ability to feel the axillary artery pulse (for the palpation method) also allow relatively easy successful implant of catheters in the axillary veins.

Keywords: hemodialysis, catheter, axillary venous, ultrasound guidance

\section{Introduction}

The ideal vascular access placement for hemodialysis patients is the arteriovenous fistula. In a significant number of patients receiving acute or chronic hemodialysis therapy, transitory or long-term catheters are necessary. For the placement of central vein catheters, the blood vessels are located via anatomical references, palpation of contiguous arteries, or visualization of the arteries with ultrasound. In recent years, ultrasound has gained popularity and is currently the technique recommended by many scientific societies and institutions. ${ }^{1-3}$ However, ultrasound is frequently not available, and thus it is still necessary, both for daily practice and for the physician in training, to know the anatomical references and structures surrounding the veins to puncture 
or to acquire the ability to recognize them by palpating the arteries adjacent to the central veins. For many years, it has been common to cannulate axillary veins in their medial segment in patients for whom it is impossible to cannulate the internal jugular veins. In addition, for many years, we used anatomical references and palpation techniques to gain access to the axillary vein. ${ }^{4}$ With the recent acquisition of ultrasound, we have a new resource for inserting catheters in the axillary vein. We present here many years of experience in the axillary implantation of catheters by various techniques.

\section{Materials and methods}

All participating patients were treated in the procedure room of the Renal Care Facility (RCF) and Intensive Care Unit (ICU) in Manizales (Caldas, Colombia, South America). The patients had an indication of dialysis (acute or chronic), and it was determined to be impossible or not recommended (patients with tracheostomy) to use the internal jugular vein or to practice arteriovenous fistula or graft. It was required that we use vascular access. The study was performed over the course of 15 years and 8 months (from January 1997-August 2012). The insertion of catheters in RCFs in recent years (since October 2007) were ultrasound-guided; in the ICUs, because of the absence of sonographic assistance, the catheters always were inserted by anatomical reference and palpation techniques. Demographic variables and procedure-related complications were evaluated. All patients or first-grade relatives gave consent to perform the procedure. It was not considered necessary to receive the approval of the ethics committee, as the procedure was not experimental and its use represented only a single choice for central venous access. In all cases, a chest X-ray was obtained to confirm the placement of the catheter. For the anatomical reference technique, the description made by Taylor and Yellowlees was used; ${ }^{5}$ in these cases, the patients were obese, and it was not possible to palpate the axillary artery pulse. For the palpation technique, it was possible to feel the artery pulse in the middle axillary region each time, and the puncture was made immediately caudal to the artery. For the ultrasound-guided technique, we used Sonofine EUS B2 (Gauges North West, Southport, UK) equipment with a lineal transducer of 5-7.5 MHz.

In all cases, the patency of the catheter was verified and the procedure was successful if the catheter gave a pump flow equal or superior to $300 \mathrm{~mL} /$ minute by at least 2 weeks. A technical failure was considered to have happened if this goal were not achieved.

\section{Statistical analysis}

We developed a database in Excel (Excel 2011 for Mac) (Microsoft Corporation, Redmond, WA, USA) that was analyzed using SPSS 14.5 (IBM Corporation, Armonk, NY, USA) and Epi-Info ${ }^{\mathrm{TM}}$ (Centers for Disease Control and Prevention, Atlanta, GA, USA). Bivariate analyses were taken as a dependent variable of the complications, and using an $\chi^{2}$ test, the comparisons were made with a statistical significance level less than 0.05 .

\section{Results}

Two nephrologists who had experience with the procedure made the insertions over a period of 15 years 8 months, from January 1997 to August 2012. We have not recorded the total number of catheter inserted in central veins that we performed over the last 15 years, but we have inserted a total of 551 catheters in RCFs and ICUs in Manizales during the last 2 years (Table 1). A total of 83 axillary catheter insertions were attempted in 51 men and 32 women, with a mean age of $59.7 \pm 16$ years ( 69 patients with chronic kidney disease and 14 with acute kidney injury). The main causes of chronic kidney disease were diabetic nephropathy and hypertensive

Table I Catheters inserted by the authors during the last 2 years

\begin{tabular}{|c|c|c|c|c|}
\hline \multirow[t]{3}{*}{ Location } & \multicolumn{4}{|c|}{ Year and type of renal failure } \\
\hline & \multicolumn{2}{|l|}{2011} & \multicolumn{2}{|l|}{2012} \\
\hline & Acute hemodialysis & Chronic hemodialysis & Acute hemodialysis & Chronic hemodialysis \\
\hline Cuffed & 0 & 54 & 2 & 35 \\
\hline Femoral & 0 & 7 & 0 & 8 \\
\hline Jugular & 0 & 46 & 2 & 24 \\
\hline Axillary & 0 & I & 0 & 3 \\
\hline Noncuffed & 100 & 124 & 119 & 116 \\
\hline Femoral & 78 & 30 & 96 & 24 \\
\hline Jugular & 22 & 90 & 22 & 89 \\
\hline Axillary & 0 & 4 & 1 & 3 \\
\hline Sum & 100 & 178 & 121 & $|5|$ \\
\hline
\end{tabular}




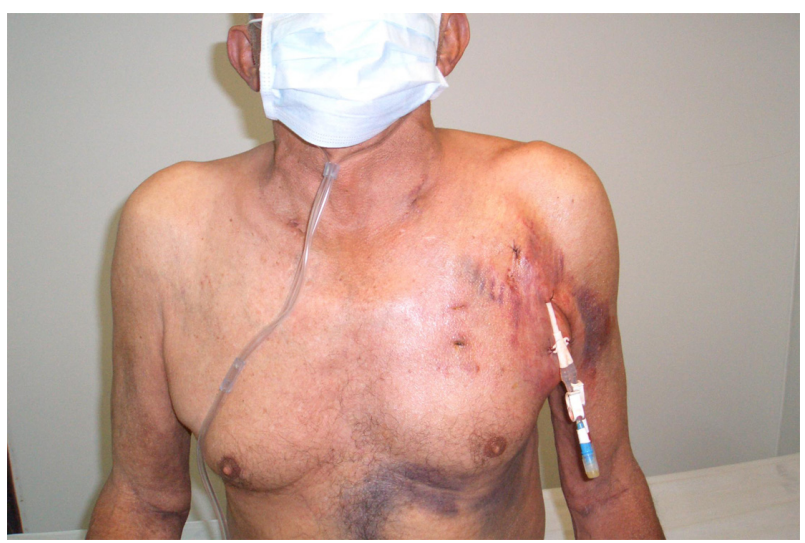

Figure I Long-term catheter in axillary vein.

nephropathy, and the main causes of acute kidney injury were acute tubular necrosis associated with renal ischemia and sepsis. Sixteen catheters were long-term (Figure 1), and 66 were temporary. In 41 procedures, the ultrasound-guided technique was used (Figure 2); in 19, the anatomical reference technique was used; in 15, the palpation of the axillary artery was used (Figure 3); and in the remaining 8 cases, the catheter was placed over a vein previously cannulated by another axillary catheter (usually when a temporary catheter was replaced by a permanent one). The main factor that prompted the use of axillary vein access in the ICU was the presence of a tracheostomy (Figure 4); in the RCF, it was the impossibility of obtaining any other access or practicing arteriovenous fistula or graft (Table 2).

The successful implantation of the catheters was achieved in 78 patients $(93.98 \%)$, while the procedure failed in five patients: two by nonlocalization of the vein (one for anatomical references and another by palpation technique)

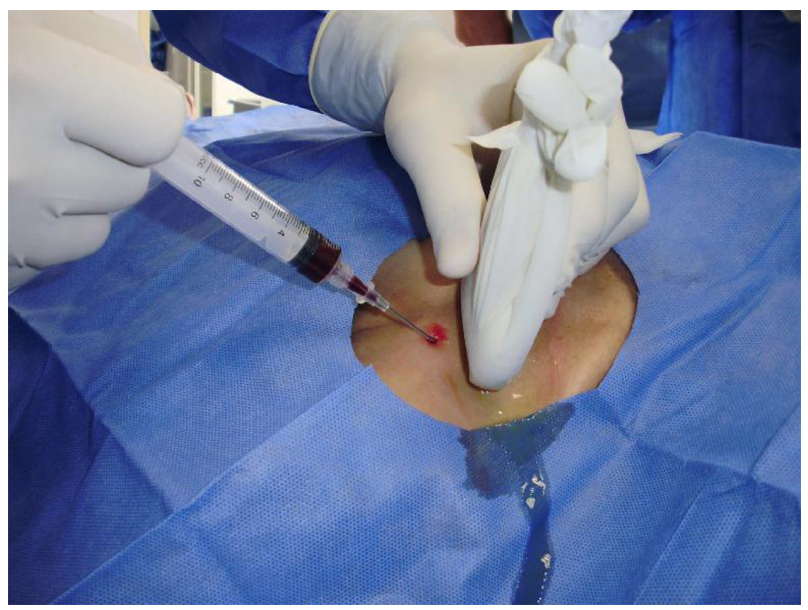

Figure 2 Ultrasound guidance axillary vein cannulation.

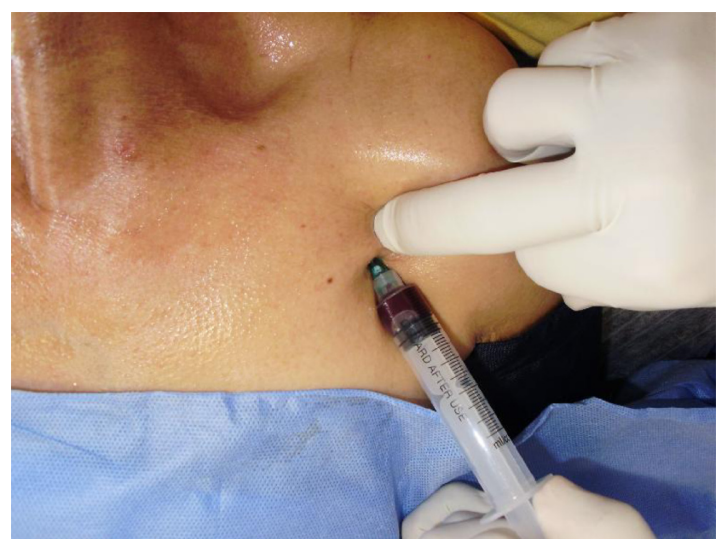

Figure 3 Palpation technique axillary vein cannulation.

and three by abnormal catheter placement (one for anatomical references and two for ultrasound-guided technique).

The number of punctures needed to obtain the proper insertion was slightly less with ultrasound guidance, but the difference was not statistically significant. The number of artery punctures was similar in all groups.

In the meantime, catheter use was retained longer in the palpation-guided and previous transitory catheter groups, but this length of time was probably longer because in these groups many long-term catheters were used (Table 3).

Analyzing both techniques, the procedure-related complications (hematoma, pneumothorax, brachial plexus injury), and the reason to remove the catheter, there were no differences among the groups (Tables 3 and 4).

In the 15 years and 8 months of the study, nonclinical evidence for axillary vein stenosis was found, but it is important to note that the maximum usage time was observed in patients with a previous catheter as a guide, at $216 \pm 222$ days.

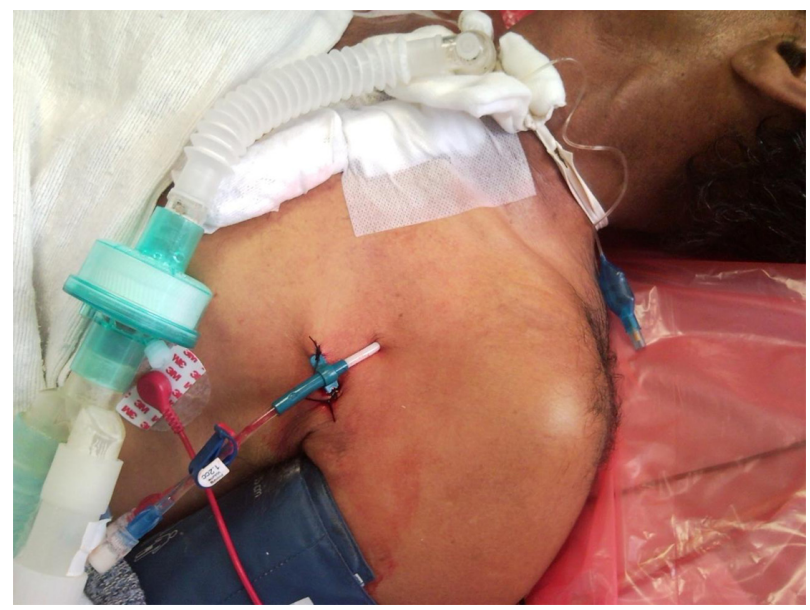

Figure 4 Axillary vein implantation in patient with tracheostomy. 
Table 2 Baseline characteristics of study patients according to the method used for the guide

\begin{tabular}{|c|c|c|c|c|}
\hline & $\begin{array}{l}\text { Anatomic guide } \\
(n=19)\end{array}$ & $\begin{array}{l}\text { Palpatory guide } \\
(n=15)\end{array}$ & $\begin{array}{l}\text { Sonographic guide } \\
(n=4 I)\end{array}$ & $\begin{array}{l}\text { Previous catheter guide } \\
(\mathrm{n}=8)\end{array}$ \\
\hline Age (years) & $52 \pm 18$ & $64 \pm 11$ & $59 \pm 17$ & $67 \pm 14$ \\
\hline \multicolumn{5}{|l|}{ Sex } \\
\hline Male & 10 & 13 & 25 & 3 \\
\hline Female & 9 & 2 & 16 & 5 \\
\hline Acute kidney injury & 4 & 5 & 5 & 0 \\
\hline Chronic kidney disease & 15 & 10 & 36 & 8 \\
\hline \multicolumn{5}{|l|}{ Kidney disease etiology } \\
\hline $\mathrm{HN}$ & 2 & 2 & 6 & 3 \\
\hline $\mathrm{DN}$ & 5 & 4 & 3 & 3 \\
\hline Unk & 6 & 3 & 5 & I \\
\hline CG & I & 0 & 2 & I \\
\hline $\mathrm{BCN}$ & 1 & I & I & 0 \\
\hline $\mathrm{CIN}$ & I & I & 0 & 0 \\
\hline Isch ATN & 1 & I & 4 & 0 \\
\hline Sept AKI & 2 & 3 & I & 0 \\
\hline $\mathrm{RN}$ & & & I & \\
\hline $\mathrm{ClntN}$ & & & 2 & \\
\hline SS & & & I & \\
\hline ON & & & 5 & \\
\hline \multicolumn{5}{|l|}{ Procedure indication } \\
\hline OANP & 15 & 10 & 37 & 8 \\
\hline Trc & 4 & 5 & 4 & 0 \\
\hline \multicolumn{5}{|l|}{ Catheter type } \\
\hline Cuffed & 2 & 3 & 4 & 8 \\
\hline Noncuffed & 17 & 12 & 37 & 0 \\
\hline
\end{tabular}

Abbreviations: HN, hypertensive nephrosclerosis; DN, diabetic nephropathy; Unk, unknown; CG, chronic glomerulonephritis; BCN, bilateral cortical necrosis; $\mathrm{CIN}$, contrast induced nephropathy; Isch ATN, ischemic acute tubular necrosis; Sept AKI, septic acute kidney injury; RN, reflux nephropathy; ClntN, chronic interstitial nephritis; SS, systemic sclerosis; ON, obstructive nephropathy; OANP, other access was not possible; Trc, tracheostomy.

Table 3 Complications

\begin{tabular}{|c|c|c|c|c|}
\hline & Anatomic guide & Palpatory guide & Sonographic guide & Previous catheter guide \\
\hline \multicolumn{5}{|l|}{ Successful insertion } \\
\hline Yes & 18 & 13 & 39 & 8 \\
\hline No & 2 & 1 & 2 & 0 \\
\hline Punctures & 30 in 20 patients & 22 in 14 patients & 55 in 41 patients & 0 \\
\hline (number, means) & (mean, I.57) & (mean, I.38) & (mean, I.34) & \\
\hline Artery punctures & 2 & 2 & i & 0 \\
\hline Average time of use (days) & $51 \pm 39$ & $123 \pm 265$ & $53 \pm 67$ & $216 \pm 222$ \\
\hline \multicolumn{5}{|l|}{ Removal cause } \\
\hline In use & 0 & 1 & 2 & 6 \\
\hline TrPD & 4 & I & 2 & I \\
\hline $\mathrm{RTr}$ & 0 & 0 & I & I \\
\hline $\mathrm{CCl}$ & I & I & 14 & \\
\hline RFR & 2 & 2 & I & \\
\hline CTro & 2 & 2 & 7 & \\
\hline Death & 3 & 6 & 8 & \\
\hline CRS & 2 & 0 & 3 & \\
\hline$A-V F$ & 4 & 0 & 2 & \\
\hline$A c R$ & 0 & 0 & I & \\
\hline Malposition & I & 0 & 0 & \\
\hline Soft tissue hematoma & I & 0 & 0 & 0 \\
\hline Pneumothorax & 0 & 0 & 0 & 0 \\
\hline Brachial plexus injury & 0 & 0 & 0 & 0 \\
\hline Axillary vein stenosis & 0 & 0 & 0 & 0 \\
\hline
\end{tabular}

Abbreviations: TrPD, transfer to peritoneal dialysis; RTr, renal transplantation; $\mathrm{CCl}$, cuffed catheter implant; RFR, renal function recovery; CTro, catheter thrombosis; CRS, catheter related sepsis; A-VF, arterio-venous fistula; AcR, accidental removal. 
Table 4 Complications analysis according to variables

\begin{tabular}{|c|c|c|c|c|c|}
\hline \multirow[t]{4}{*}{ Variables } & \multicolumn{4}{|c|}{ Complication } & \multirow[t]{4}{*}{$P$} \\
\hline & \multicolumn{2}{|c|}{ Hematoma } & \multirow{2}{*}{\multicolumn{2}{|c|}{$\begin{array}{l}\text { Artery } \\
\text { puncture }\end{array}$}} & \\
\hline & \multirow[t]{2}{*}{$\bar{n}$} & \multirow[t]{2}{*}{$\%$} & & & \\
\hline & & & $n$ & $\%$ & \\
\hline \multicolumn{6}{|l|}{ Guide } \\
\hline Anatomic & I & 33.3 & 2 & 66.7 & $\mathrm{~N}$ \\
\hline Sonographic & 0 & 0.0 & I & 100.0 & $\mathrm{~N}$ \\
\hline Impossibility & 0 & 0.0 & I & 100.0 & $\mathrm{~N}$ \\
\hline Palpatory & 0 & 0.0 & 2 & 100.0 & $\mathrm{~N}$ \\
\hline \multicolumn{5}{|l|}{ Sex } & \\
\hline Female & 1 & 25.0 & 3 & 75.0 & NS \\
\hline Male & 0 & 0.0 & 3 & 100.0 & Ns \\
\hline \multicolumn{5}{|l|}{ Renal failure type } & \\
\hline Acute & I & 33.3 & 2 & 66.7 & NS \\
\hline Chronic & 0 & 0.0 & 4 & 100.0 & NS \\
\hline \multicolumn{5}{|l|}{ Kidney disease etiology } & \\
\hline $\mathrm{BCN}$ & 0 & 0.0 & $\mathrm{I}$ & 100.0 & NS \\
\hline DN & 0 & 0.0 & I & 100.0 & NS \\
\hline SEPT AKI & I & 50.0 & I & 50.0 & NS \\
\hline Unk & 0 & 0.0 & 3 & 100.0 & NS \\
\hline \multicolumn{5}{|l|}{ Procedure indication } & \\
\hline OANP & 0 & 0.0 & 5 & 100.0 & NS \\
\hline Trc & I & 50.0 & 1 & 50.0 & NS \\
\hline \multicolumn{5}{|l|}{ Catheter type } & \\
\hline Noncuffed & I & 14.3 & 6 & 85.7 & NS \\
\hline Cuffed & 0 & 0.0 & 0 & 0.0 & NS \\
\hline \multicolumn{5}{|l|}{ Result } & \\
\hline Successful & I & 20.0 & 4 & 80.0 & NS \\
\hline Failure & 0 & 0.0 & 2 & 100.0 & NS \\
\hline \multicolumn{5}{|l|}{ Vein } & \\
\hline Right & I & 33.3 & 2 & 66.7 & NS \\
\hline Left & 0 & 0.0 & 2 & 100.0 & NS \\
\hline Neither & 0 & 0.0 & 2 & 100.0 & NS \\
\hline \multicolumn{5}{|l|}{ Removal cause } & \\
\hline Ctro & 0 & 0.0 & I & 100.0 & NS \\
\hline Death & 0 & 0.0 & 1 & 100.0 & NS \\
\hline In axillary artery & 0 & 0.0 & 1 & 100.0 & NS \\
\hline RFR & I & 50.0 & 1 & 50.0 & NS \\
\hline TrPD & 0 & 0.0 & I & 100.0 & NS \\
\hline Not applicable & 0 & 0.0 & 1 & 100.0 & NS \\
\hline \multicolumn{5}{|l|}{ Age group } & \\
\hline Younger than 50 years & I & 20.0 & 4 & 80.0 & NS \\
\hline Between 50 and 75 years & 0 & 0.0 & 2 & 100.0 & NS \\
\hline Older than 75 years & 0 & 0.0 & 0 & 0.0 & NS \\
\hline \multicolumn{5}{|l|}{ Time of use } & \\
\hline Less than 15 days & 0 & 0.0 & 3 & 100.0 & NS \\
\hline Between 15 and 30 days & I & 33.3 & 2 & 66.7 & \\
\hline Between 30 and 60 days & 0 & 0.0 & 1 & 100.0 & NS \\
\hline
\end{tabular}

Abbreviations: $\mathrm{BCN}$, bilateral cortical necrosis; $\mathrm{DN}$, diabetic nephropathy; Sept AKI, septic acute kidney injury; Unk, unknown; OANP, other access was not possible; Trc, tracheostomy; CTro, catheter thrombosis; RFR, renal function recovery; TrPD, transfer to peritoneal, dialysis; NS, not significant.

\section{Discussion}

Different methods are used to implant central vein catheters; the success of the procedure is directly related to daily experience with the technique. The use of anatomical references and the palpation method to identify the veins before the cannulation attempt is based on the assumption of a given vessel location. With this information in mind, the physician then performs a blind insertion of the needle until obtaining blood. In the RCFs and the ICUs of Manizales, it is common to puncture different venous beds, ${ }^{4-9}$ one of which is the axillary vein. In a relatively recent publication, we presented our experience with the axillary vein cannulation by anatomical guidance and by palpation of the adjacent axillary artery. ${ }^{4}$

The axillary veins have their origin in the axillary fold, and they turn into the subclavian vein at the level of the external rim of the first costal arch (Figure 5). They are divided into three segments, proximal, middle (posterior), and distal, related to the pectoralis minor muscle. The muscle's location is entirely extrathoracic, and its position does not change with the rotation of head, such as with jugular access. ${ }^{10}$ Axillary vein cannulation is not easy because of its deep location, and for this reason it is necessary to go through the entire pectoralis major muscle (Figure 6). The muscle's palpation by poorly trained hands is difficult in edematous patients or in those with a big adipose panicle. This is why we need both proper knowledge of the anatomical references of the infraclavicular region or the ability to locate the adjacent axillary artery by palpation. In spite of the difficulty previously mentioned in the location of the axillary vein, its use is secure because

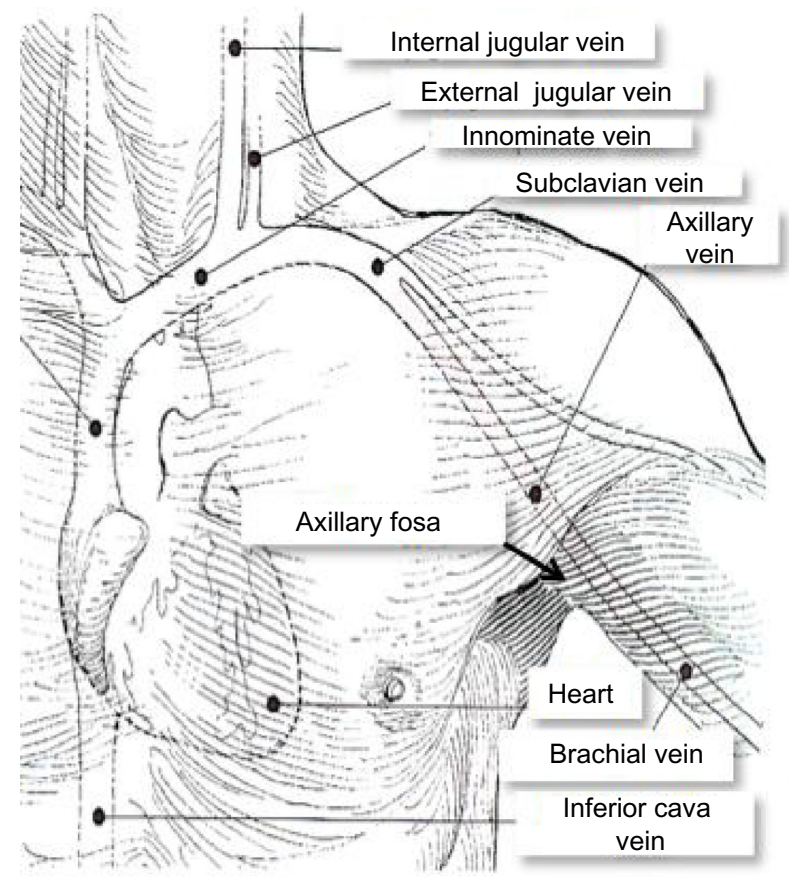

Figure 5 Axillary Catheter For Hemodialysis, an Alternative Vascular Access. Nefrologia. 2008; 1:77-8I.

Note: () 2008 Sociedad Española De Nefrologia. Reproduced with permission from Restrepo Valencia CA. Catéter axilar para hemodiálisis, un acceso vascular alternativo. [Axillary catheter for hemodialysis, an alternative vascular access]. Nefrologia. 2008;28(I):77-8I. ${ }^{4}$ 


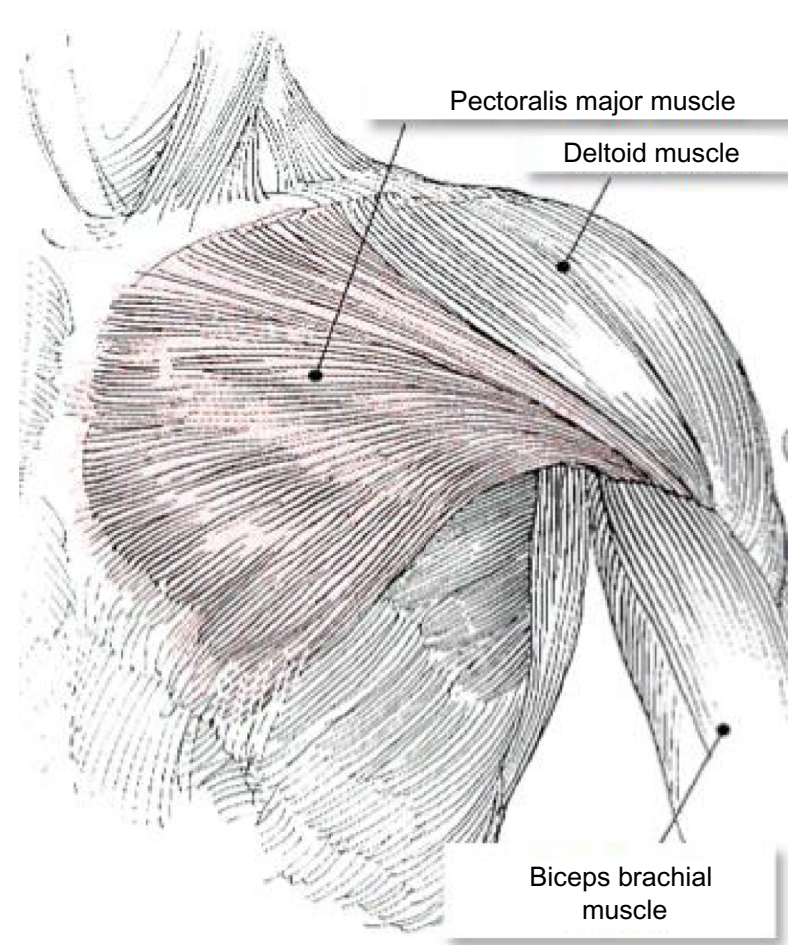

Figure 6 Pectoralis major muscle.

Note: (C) 2008 Sociedad Española De Nefrologia. Reproduced with permission from Restrepo Valencia CA. Catéter axilar para hemodiálisis, un acceso vascular alternativo. [Axillary catheter for hemodialysis, an alternative vascular access]. Nefrologia. 2008;28(I):77-8I. ${ }^{4}$

of its extrathoracic position, as it is entirely surrounded by soft tissues, and because of its constant anatomical relation adjacent to the axillary artery.

The use of ultrasound guide could overcome, in theory, the previously mentioned difficulties in locating the axillary vein by performing the procedure with echographic and realtime visualization of the vein and the needle.

In 2001, the Agency for Healthcare Research and Quality, in the document "Making Health Care Safer: A Critical Analysis of Patient Safety Practices," recommended using ultrasound for the insertion of central vein catheters. ${ }^{11}$

To use a sonographic guide, transducers with a frequency major or equal to $7 \mathrm{MHz}$ are recommended because they give superior resolution of superficial structures.

In different publications, complications related to central vein access were analyzed for patients not receiving dialysis, and a significant reduction in the complication index was detected using ultrasound as a guide, as well as a lower level of technique failure, a superior possibility of success in the first puncture, and a lower index of artery punctures. ${ }^{12-14}$

Guidelines for performing ultrasound-guided vascular cannulation were recently presented by the American Society of Echocardiography and the Society of Cardiovascular
Anesthesiologists, ${ }^{15}$ recommending that physicians with proper training use real-time ultrasound whenever possible during the internal jugular vein cannulation, both to obtain a better result and to reduce the incidence of associated complications with big catheter insertions. This recommendation is in category A and has level 1 evidence. For subclavian vein implantation, this recommendation is in category A and has level 3 evidence.

The central vein catheter implantation for hemodialysis could generate a bigger risk, because of its big diameter and associated conditions, such as uremic environment, that predispose to hemorrhagic complications. For this reason, the Kidney Disease Outcomes Quality Initiative 2006 guidelines recommend sonographic identification of central veins before the insertion procedure for hemodialysis catheters. ${ }^{1}$

In dialysis patients, a recent meta-analysis and systematical review that included seven proofs including 830 central vein catheters inserted by ultrasound guide versus anatomical references concluded that the use of an ultrasound guide significantly reduced the risk of failing during the catheter implantation, the first puncture failure, artery puncture, hematoma, and in general, in the total number of punctures. This study had the inconvenience of not clearly discriminating the vascular beds used for puncture. ${ }^{16}$

In our experience, in recent years, with the acquisition of ultrasound equipment, ultrasound guidance has been routinely implemented during the insertion of axillary catheters in the RCF whenever jugular vein access was not possible. However, outside the RCF, we continued using nonultrasound guidance techniques.

In a large number of procedures, we observed that implantation of catheters in the axillary vein is relatively easy if you have the training, and ultrasound guidance achieved a slight decrease in the number of punctures without a significant reduction in complications associated with the procedure (Table 3). It is important to note that the number of procedures performed using ultrasound guidance exceeds that of each of the other groups, although it is likely that if we extended the number of the latter, the results may be different.

It is not our intention to go against current international recommendations, but we think future nephrologists first need to be familiar with the techniques of insertion of hemodialysis catheters by anatomical reference and palpation of arteries adjacent to venous beds (axillary, carotid, and femoral) before learning the ultrasound-guided technique. This recommendation could equip the nephrologist with the ability to successfully face difficult situations when no ultrasound guidance is available. 


\section{Disclosure}

The authors report no conflicts of interest in this work.

\section{References}

1. KDOQI Advisory Board Members. Clinical practice guidelines and clinical practice recommendations 2006. Am J Kidney Dis. 2006;48:S1-S322.

2. American Society of Anesthesiologists Task Force on Central Venous Access, Rupp SM, Apfelbaum JL, et al. Practice guidelines for central venous access: a report by the American Society of Anesthesiologists Task Force on Central Venous Access. Anesthesiology. 2012;116(3): 539-573.

3. Caring for Australasians with Renal Impairment. Insertion of Catheters. Caring for Australasians with Renal Impairment; 2012. Available from: http://www.cari.org.au/DIALYSIS_va_published/Insertion $\% 20$ of $\% 20$ catheters.pdf. Accessed September 26, 2012.

4. Restrepo Valencia CA. Catéter axilar para hemodiálisis, un acceso vascular alternativo. [Axillary catheter for hemodialysis, an alternative vascular access]. Nefrologia. 2008;28(1):77-81. Spanish.

5. Taylor BL, Yellowlees I. Central venous cannulation using the infraclavicular axillary vein. Anesthesiology. 1990;72(1):55-58.

6. Restrepo Valencia CA, Buritica Barragán CM. Implantación de catéteres para hemodiálisis en vena innominada, una ruta poco utilizada. [Implanting haemodialysis catheters in the brachiocephalic vein: a little-used approach]. Nefrologia. 2009;29(4):354-357. Spanish.

7. Restrepo Valencia CA, Buritica Barragán CM, Arango A. Catéter en vena cava superior para hemodiálisis entre los últimos recursos en hemitórax superior. [Catheter in the superior vena cava for hemodialysis as a last resort in superior hemithorax]. Nefrologia. 2010;30(4):463-466. Spanish.

8. Restrepo CA, Chacon JA, Villota DM. Seguridad de la implantación de catéteres yugulares para hemodiálisis y utilidad de la radiografia P-A de tórax posprocedimiento. [Safety related to the implantation of jugular catheters for hemodialysis and usefulness of PA chest X rays post procedure]. Acta Med Colomb. 2008;33:68-74. Spanish.
9. Cesar A. Restrepo V. Unusual vascular access for hemodialysis therapies In: Göoz M, editor. Chronic Kidney Disease. Rijeka, Croatia: InTech; 2012. Available from: http://www.intechopen.com/books/chronickidney-disease/unusual-vascular-access-for-hemodialysis-therapies. Accessed August 3, 2012.

10. Troianos CA, Kuwik RJ, Pasqual JR, Lim AJ, Odasso DP. Internal jugular vein and carotid artery anatomic relation as determined by ultrasonography. Anesthesiology. 1996;85(1):43-48.

11. Rothschild JM. Ultrasound guidance of central vein catheterization. In: Making Health Care Safer: A Critical Analysis of Patient Safety Practices. AHRQ Publication No 01-E058. Rockville, MD: Agency for Healthcare Research and Quality; 2001:245-253.

12. Hatfield A, Bodenham A. Difficult central venous access and the role of ultrasound. Current Anaesthesia Crit Care. 2002;13(4):185-193.

13. Hind D, Calvert N, McWilliams R, et al. Ultrasonic locating devices for central venous cannulation: meta-analysis. BMJ. 2003;327(7411):361

14. Augoustides JG, Horak J, Ochroch AE, et al. A randomized controlled clinical trial of real-time needle-guided ultrasound for internal jugular venous cannulation in a large university anesthesia department J Cardiothorac Vasc Anesth. 2005;19(3):310-315.

15. Troianos CA, Hartman GS, Glas KE, et al; Councils on Intraoperative Echocardiography and Vascular Ultrasound of the American Society of Echocardiography. Guidelines for performing ultrasound guided vascular cannulation: recommendations of the American Society of Echocardiography and the Society of Cardiovascular Anesthesiologists. J Am Soc Echocardiogr. 2011;24(12):1291-1318.

16. Rabindranath KS, Kumar E, Shail R, Vaux E. Use of real-time ultrasound guidance for the placement of hemodialysis catheters: a systematic review and meta-analysis of randomized controlled trials Am J Kidney Dis. 2011;58(6):964-970.

\section{Publish your work in this journal}

The International Journal of Nephrology and Renovascular Disease is an international, peer-reviewed open-access journal focusing on the pathophysiology of the kidney and vascular supply. Epidemiology, screening, diagnosis, and treatment interventions are covered as well as basic science, biochemical and immunological studies. The journal welcomes

\section{Dovepress}

original research, clinical studies, reviews \& evaluations, expert opinion and commentary, case reports and extended reports. The manuscript management system is completely online and includes a very quick and fair peerreview system, which is all easy to use. Visit http://www.dovepress.com/ testimonials.php to read real quotes from published authors. 